\title{
MANUFACTURING PERFORMANCE MEASUREMENT USING FUZZY MULTI-ATTRIBUTE UTILITY THEORY AND Z-NUMBER
}

\begin{abstract}
Summary
The Earned Value Management (EVM) has been extensively employed in the literature for analysing the schedule and cost performance indexes. However, the effects of risk factors on the project success have been previously ignored in the project management conventional context. In this paper, a well-organized project control and monitoring system is developed by incorporating the EVM basic principles, risk analysis, and utility theory for improving the performance of manufacturing systems. Weight values corresponding to the schedule performance index (SPI), the cost performance index (CPI), and the risk performance index (RPI) are calculated based on expert judgments using Z-number and Analytic Hierarchy Process (Z-AHP). Finally, a Multi-Attribute Utility Theory (MAUT) and Multi-Objective Linear Programming (MOLP) under fuzzy condition are utilized to demonstrate the applicability of the proposed approach. Sensitivity analysis indicated the risk performance is the most sensitive when compared with the schedule and the cost index. The approach given in this paper can be further employed by both academicians and managers in heavy intensive manufacturing systems.
\end{abstract}

Keywords: $\quad$ Manufacturing systems, Multi-Objective Linear Programming (MOLP), Earned Value Management (EVM), Risk analysis, Z-Number

\section{Introduction}

The Earned Value Management (EVM) is a famous tool assisting project managers in checking the project schedule and budget to see whether they are on track. The EVM provides an excellent insight into the current trend in the project as well as a study on the planning of the project budget and the time required for the project completion. Traditional EVM-based control systems are used to analyse and detect the current schedule and cost performance indexes. In addition, there are some other models tending to provide a good insight into the cost required for the completion of the project. Thus, the schedule performance index SPI(t) has been presented as a new metric in the EVM context where the schedule performance index has been calculated based on the earned schedule and not based on the conventional earned value.

The EVM has rarely been merged with other fields under investigation. The EVM has also been incorporated within financial issues and a new index, entitled financial performance 
index, has been presented; here, financial initiatives have been incorporated in the standard EVM and performance indexes have been revised based on financial achievements.

The problem under investigation by many researchers is related to how the effect of unknown factors influencing the performance measurement and analysis is considered. In order to reach these objectives, mathematical models are implemented in the standard approaches. However, the problem that always remains is how project management techniques can be merged with the production and manufacturing systems in order to enhance performance measurement. Here, the main issue is that an analyst has to take several influencing factors (time, cost, risk) into consideration simultaneously. Therefore, a multiattribute utility theory was used for the integration of all sub-systems into a whole.

\section{Literature Review}

In order to review the literature, first, we categorize the studies carried out in terms of the earned value, production performance, and multi-attribute utility theory.

The EVM has been extensively employed in the project management context ([1]-[5]). It is also noticed that the EVM has not only been used in the project management areas but has also been applied in other related areas such as production planning and control. The EVM is, therefore, used as a control mechanism in production systems, especially in multiperiod - multi-product production planning systems $[6,7,8]$.

For example, the studies $[2,9,10]$ discussed how to improve the accuracy of schedule performance index. As for mathematical modelling, one can summarize that fuzzy logic and multi-objective models have been incorporated mostly through the EVM ([11, 12]).

Performance measurement in production systems has been investigated in the studies listed below:

Data envelopment analysis (DEA) used for performance measurement and the target setting of manufacturing systems was presented; its use led to the identification of performance changes [13]. The Multiple Attribute Decision Making (MADM) techniques were evaluated as a potential tool for making decisions in performance measurement systems [14]. Performance measurement was transformed into an MADM method and a performance measurement model based on the fuzzy analytical network process (FANP) was proposed [15]. In [16], the focus of the research was on the characteristics, features and roles of performance measurement systems in Czech large-size manufacturing companies. The application of non-financial performance measurement system among manufacturing companies was examined in [17] and an attempt was made to explore the association between the size of the company, the business environment, the use of non-financial performance measures, and the modern manufacturing technology. On the other hand, several mathematical models have been found in the literature. The most well-known can be mentioned: multi-attribute utility theory [18], control methods [19, 20], multiple-criteria decision making, which included Multi-Objective Linear Programming (MOLP) and MultiAttribute Decision Making (MADM)), for example in [22] and [23], and fuzzy set theory in [24]. The most common problem that project managers encounter is how risk factors affecting the EVM can be incorporated and how such risks can be dealt with. We therefore need to develop a risk-based model as well as a well-organized project management monitoring system which should function under uncertain conditions as well. In order to attain this objective, the structure of this paper is divided into sections dealing with the problem statement, modelling, and the analysis of obtained results. In the last section, we summarize our findings and novel contributions. 


\section{Problem statement}

The problem under consideration in this paper consists of a manufacturing project (customer-based orders) which will be monitored throughout several periods. In order to measure the performance of the manufacturing system, schedule, cost, and risk-based indexes have to be closely monitored at the end of each period to evaluate the status of each customer's order. The risk here refers to machine failure, breakdown, lack of details on engineering drawings, variation in machine processing times, changes in design due to employer's re-order, etc.

The project/production manager aims at monitoring the overall status of manufacturing according to integration of all the indexes that affect the overall analysis. Here, a multi-utility function for each individual performance index is proposed to meet the coverage of all influencing factors through a comprehensive analysis. After running the multi-attribute utility model, the obtained results can be elaborated using the Exponentially Weighted Moving Average (EWMA) for the control and monitoring of the obtained function. The model provides the following contributions compared with the existing models in the literature:

- Developing an integrated manufacturing, monitoring, and control system;

- Applying the utility theory in EVM that is applicable in production and manufacturing systems;

- Analysing the effect of risk factors on production systems:

- Combination of utility theory and multi -attribute decision making in analysing manufacturing projects.

\section{The proposed approach}

The approach given in this paper consists of several phases as presented below:

\section{Notations:}

$W_{S P I}$ : Schedule performance importance from the production manager's point of view

$W_{C P I}$ : Cost performance importance given by the production manager

$W_{R P I}$ : The importance of risk performance index from the production manager's point of view

$U(S P I)$ : Utility function corresponding to schedule performance

$U(C P I)$ : Utility function corresponding to cost performance

$U(R P I)$ : Utility function corresponding to risk performance

$U_{\text {Total }}$ : Total utility function

$\lambda_{S P I}$ : Satisfaction degree related to schedule performance

$\lambda_{C P I}$ : Satisfaction degree related to cost performance

$\lambda_{R P I}$ : Satisfaction degree related to risk performance

$\mu[U(S P I)]$ : Membership function corresponding to schedule performance ([0-1])

$\mu[U(C P I)]:$ Membership function corresponding to cost performance $([0-1])$

$\mu[U(R P I)]:$ Membership function corresponding to risk performance ([0-1])

$S P I^{-}$: Lower bound for schedule performance given by the production manager

$C P I^{-}$: Lower bound for cost performance given by the production manager

$R P I^{-}$: Lower bound for risk performance given by the production manager

$S P I^{+}$: Upper bound for schedule performance

$C P I^{+}$: Upper bound for cost performance

$R P I^{+}$: Upper bound for risk performance 
The following steps have been taken into consideration for the modelling of the problem:

Step 1- Read the product specifications based on existing engineering drawings

This step is defined in order to put engineering specifications within the scope of work.

Step 2- Determine the budget for all products

The budgetary estimate for all products can be determined according to cost allocation for each product.

Step 3- Set up cost control accounts based on accounting principles

In order to manage costs, there is a need for a unique cost coding in such a way that cost allocation can be easily conducted.

Step 4- Develop risk breakdown structure (RBS)

Besides work breakdown structure, a project has to build up a risk breakdown structure in order to assign risk factors to RBS.

Step 5- Distribute total budgetary estimate on production schedule (PV) progress.

The planned value can be determined based on multiplying the budget on the planned

Step 6- Calculate earned value (EV $=$ Budget * \% progress $)$

The earned value refers to budgeted costs of works performed. The progress here refers to actual progress resulting in actual values of works done.

Step 7- Calculate total actual costs based on produced items (AC)

The actual costs are equal to all expenses paid for manpower, material, and machinery.

Step 8- Calculate schedule performance index (SPI = EV / PV)

If the SPI is equal to 1 , it implies the ideal case for managing the time schedule.

Step 9- Calculate cost performance $(\mathrm{CPI}=\mathrm{EV} / \mathrm{AC})$

If CPI is equal to one, it implies the "on- budget" situation. If CPI starts falling, it is indicated that the budgetary estimate is not sufficient to accomplish tasks.

Step 10- Calculate risk performance index $=\left[\operatorname{SUM}\left(\left(\mathrm{r}_{\mathrm{i}}\right) * \mathrm{~W}_{\mathrm{i}}\right)\right] /\left[\mathrm{SUM}\left(\mathrm{W}_{\mathrm{i}}\right)\right]$

Risk performance index is calculated based on the average weight of risk factors.

Step 11- Develop an integrated utility function for schedule, cost and risk

The SPI, CPI, and RPI should be merged into one unique function, i.e. an integrated utility function.

Step 12- Calculate utility function $=\mathrm{U}(\mathrm{SPI})$

Step 13- Calculate utility function $=\mathrm{U}(\mathrm{CPI})$

Step 14- Calculate utility function= U(RPI)

Step 15-Calculate the aggregated utility function

$$
U_{\text {Total }}=w_{S P I} * U(S P I)+w_{C P I} * U(C P I)+w_{R P I} * U(R P I)
$$

\section{The Base Model}

It is assumed the performance indexes are mutually independent of additive independence. Thus, based on the utility theory principles, the aggregated utility function relevant to the schedule, cost and risk factors has been incorporated as Eq. (1).

A fuzzy multiple-objectives linear model based on the utility theory and fuzzy logic is given as model (2):

$$
\begin{aligned}
& \operatorname{Max} Z_{1}=U(S P I) \\
& M a x Z_{2}=U(C P I) \\
& M a x Z_{3}=U(Q P I)
\end{aligned}
$$




\section{Fuzzy Multi-Objective Linear Programming}

In a multi-objective model, several objectives have to be simultaneously optimized considering different membership functions [25], as model (3):

$$
\begin{aligned}
& \text { Maximize } \quad \sum_{g=1}^{G} W_{g} \lambda_{g} \\
& \text { S.t. } \\
& \lambda_{g} \leq f_{g}(X), \quad g=1, \ldots, G \\
& \mathrm{C} \leq C_{g} \\
& \mathrm{X} \geq 0 \\
& \lambda_{g} \in\left[\begin{array}{ll}
0 & 1
\end{array}\right], \quad g=1, \ldots, G \\
& \text { Where } \quad \sum_{g=1}^{G} W_{g}=1
\end{aligned}
$$

Using the approaches given by [25] and [26], the above mentioned model can be transformed to a constrained single objective model (4).

$$
\begin{aligned}
& \operatorname{Max} Z=W_{S P I} * \lambda_{S P I}+W_{C P I} * \lambda_{C P I}+W_{Q P I} * \lambda_{Q P I} \\
& \lambda_{S P I} \leq \mu[U(S P I)] \\
& \lambda_{C P I} \leq \mu[U(C P I)] \\
& \lambda_{Q P I} \leq \mu[U(R P I)] \\
& \lambda_{S P I}, \lambda_{C P I} \text { and } \lambda_{R P I} \in\left[\begin{array}{ll}
0 & 1
\end{array}\right]
\end{aligned}
$$

The membership functions of $\mu[U(S P I)], \mu[U(C P I)]$ and $\mu[U(R P I)]$ can be obtained by Eqs (5) - (7) (using Eq. (15) from [27]).

$$
\begin{aligned}
& \mu[U(S P I)]=\frac{U(S P I)-S P I^{-}}{S P I^{+}-S P I^{-}} \\
& \mu[U(C P I)]=\frac{U(C P I)-C P I^{-}}{C P I^{+}-C P I^{-}} \\
& \mu[U(R P I)]=\frac{U(R P I)-R P I^{-}}{R P I^{+}-R P I^{-}}
\end{aligned}
$$

For considering the fitness and normalization of utility functions, Eqs (8) - (10) have been employed [28].

$$
\begin{aligned}
& U(S P I)=\frac{S P I-M I N(S P I)}{M A X(S P I)-M I N(S P I)} \\
& U(C P I)=\frac{C P I-M I N(C P I)}{M A X(C P I)-M I N(C P I)} \\
& U(R P I)=\frac{R P I-M I N(R P I)}{M A X(R P I)-M I N(R P I)}
\end{aligned}
$$

Thus, based on expert judgments, the weight values related to SPI, CPI, and RPI are calculated using the Z-number AHP (Z-AHP).

\section{Fuzzy AHP}

Fuzzy AHP has been widely used, e.g. in $[29,30]$. It has a pairwise matrix such as the one in (11).

$$
\tilde{A}=\left[\begin{array}{cccc}
1 & \tilde{a}_{12} & \ldots & \tilde{a}_{1 n} \\
\tilde{a}_{21} & 1 & \ldots & \tilde{a}_{2 n} \\
\ldots & \ldots & \ldots & \ldots \\
\tilde{a}_{n 1} & \tilde{a}_{n 2} & \ldots & 1
\end{array}\right]=\left[\begin{array}{cccc}
1 & \tilde{a}_{12} & \ldots & \tilde{a}_{1 n} \\
1 / \tilde{a}_{12} & 1 & \ldots & \tilde{a}_{2 n} \\
\ldots & \ldots & \ldots & \ldots \\
1 / \tilde{a}_{1 n} & 1 / \tilde{a}_{2 n} & \ldots & 1
\end{array}\right]
$$


This matrix includes the following fuzzy numbers (12):

$$
\tilde{\alpha}_{\mathrm{ij}}= \begin{cases}1 & i=j \\ \tilde{1}, \tilde{3}, \tilde{5}, \tilde{7}, \tilde{9} \text { or } & i \neq j\end{cases}
$$

$S_{i}$ will be calculated for each row of the pairwise matrix using Eq. (13). Also, $S_{i}$ can be a triangular fuzzy number such as $\left(l_{i}, m_{i}, u_{i}\right)$.

$$
S_{i}=\sum_{j=1}^{m} M_{g i}^{j} \otimes\left[\sum_{i=1}^{n} \sum_{j=1}^{m} M_{g i}^{j}\right]^{-1}
$$

$M_{g i}^{j}$ is the value of triangular fuzzy number in the pairwise matrix. Then, the value of fuzzy synthetic extent with respect to the $i^{\text {th }}$ alternative is expressed as Eq. (14). The values of $\sum_{j=1}^{m} M_{i j}, \sum_{\mathrm{i}=1}^{\mathrm{n}} \sum_{\mathrm{j}=1}^{\mathrm{m}} \mathrm{M}_{\mathrm{ij}}$ and $\left[\sum_{i=1}^{n} \sum_{j=1}^{m} M_{i j}\right]^{-1}$ are calculated using (14):

$$
\begin{aligned}
& \sum_{j=1}^{m} M_{i j}=\left(\sum_{j=1}^{m} l_{i j}, \sum_{j=1}^{m} m_{i j}, \sum_{j=1}^{m} u_{i j}\right), i=1,2, \ldots, n \\
& \sum_{\mathrm{i}=1}^{\mathrm{n}} \sum_{\mathrm{j}=1}^{\mathrm{m}} \mathrm{M}_{\mathrm{ij}}=\left(\sum_{\mathrm{i}=1}^{\mathrm{n}} \sum_{\mathrm{j}=1}^{\mathrm{m}} 1_{\mathrm{ij}}, \sum_{\mathrm{i}=1}^{\mathrm{n}} \sum_{\mathrm{j}=1}^{\mathrm{m}} \mathrm{m}_{\mathrm{ij}}, \sum_{\mathrm{i}=1}^{\mathrm{n}} \sum_{\mathrm{j}=1}^{\mathrm{m}} \mathrm{u}_{\mathrm{ij}}\right) \\
& {\left[\sum_{i=1}^{n} \sum_{j=1}^{m} M_{i j}\right]^{-1}=\left(\frac{1}{\sum_{i=1}^{n} \sum_{j=1}^{m} u_{i j}}, \frac{1}{\sum_{i=1}^{n} \sum_{j=1}^{m} m_{i j}}, \frac{1}{\sum_{i=1}^{n} \sum_{j=1}^{m} l_{i j}}\right)}
\end{aligned}
$$

The degree of possibility of $M_{1} \geq M_{2}$ is calculated using (15):

$$
V\left(M_{1} \geq M_{2}\right)=\sup _{x \geq y}\left[\min \left(\mu_{M_{1}}(x), \mu_{M_{2}}(y)\right)\right]
$$

For calculating the $V\left(s_{j} \geq s_{i}\right)$, the formula (16) can be used.

$$
V\left(s_{j} \geq s_{i}\right)=\operatorname{height}\left(s_{i} \cap s_{j}\right)= \begin{cases}1 & \text { if } m_{2} \geq m_{1} \\ 0 & \text { if } l_{1} \geq u_{2} \\ \frac{l_{i}-u_{j}}{\left(m_{j}-u_{j}\right)-\left(m_{i}-l_{i}\right)} & \text { otherwise }\end{cases}
$$

Consider that $\mathrm{d}^{\prime}\left(A_{i}\right)=\min V\left(S_{i} \geq S_{k}\right) \forall k=1,2, \ldots, n \quad k \neq i$; for $A_{i}$, we have $i=1,2, \ldots, n$. The weight factor can be obtained by (17):

$$
W^{\prime}=\left(\mathrm{d}^{\prime}\left(A_{1}\right), \mathrm{d}^{\prime}\left(A_{2}\right), \ldots, \mathrm{d}^{\prime}\left(A_{n}\right)\right)^{T}
$$
number.

Via normalization, the weight vector can be obtained using (18), where it is a crisp

$$
W=\left(\mathrm{d}\left(A_{1}\right), \mathrm{d}\left(A_{2}\right), \ldots, \mathrm{d}\left(A_{n}\right)\right)^{T}
$$




\section{Z-AHP}

In this section, we proposed the Z-number Analytic Hierarchy Process (AHP) for calculating the importance level of each objective involved in the production criteria (time, cost, and risk). In order to determine the weight factors corresponding to each objective, fuzzy logic, the Z-number concept in particular, is used due to the existence of imprecise data given by experts in the production and manufacturing system, $x$ [31]. The Z-number was introduced for the first time in 2011 [32]. The procedure to apply the method is given as follows [33]:

1. Transform the second part (reliability) into a crisp value using Eq. (19):

$$
\alpha=\frac{\int x \mu_{\tilde{B}}(x) \mathrm{d} x}{\int \mu_{\tilde{B}}(x) \mathrm{d} x}
$$

where $\int$ indicates an algebraic integration.

2. Add the weight of the second part $(\alpha)$ to the first part. The weighted Z-number is illustrated in Eq. (20):

$$
\tilde{\mathrm{Z}}^{\alpha}=\left\{\left\langle\mathrm{x}, \mu_{\widetilde{\mathrm{A}}^{\alpha}}(\mathrm{x})\right\rangle \mid \mu_{\widetilde{\mathrm{A}}^{\alpha}}(\mathrm{x})=\alpha \mu_{\widetilde{\mathrm{A}}}(\mathrm{x})\right\}
$$

3. Convert the weighted Z-number into a normalized fuzzy number using Eq. (21).

$$
\tilde{\mathrm{Z}}^{\prime}=\sqrt{\alpha} \times \widetilde{\mathrm{A}}^{\alpha}=\left(\sqrt{\alpha} \times \mathrm{a}_{1}, \sqrt{\alpha} \times \mathrm{a}_{2}, \sqrt{\alpha} \times \mathrm{a}_{3}, \sqrt{\alpha} \times \mathrm{a}_{4}\right)
$$

However, the initial Z-number is transformed to a normalized fuzzy number (for more details the reader can refer to [33] and [34]).

Thus, based on expert judgments, weight values related to SPI, CPI, and RPI using ZAHP are utilized based on the data given.

\section{Numerical Example}

In this study, the data collected refer to 20 months of a production project which is randomly generated. The SPI and CPI have been fitted on Uniform distribution functions (0.7-1.1) and RPI follows Uniform (0.6-0.9) based on the historical information extracted from previous production planning horizons. The data is summarized in Table 1 and illustrated in Fig. 1.

Table 1 The obtained data

\begin{tabular}{|c|c|c|c|c|c|c|c|}
\hline Month & SPI & CPI & QPI & Month & SPI & CPI & QPI \\
\hline $\mathbf{1}$ & 0.93 & 0.98 & 0.86 & 11 & 0.79 & 0.97 & 0.81 \\
\hline 2 & 1.02 & 0.85 & 0.81 & 12 & 0.91 & 1.03 & 0.88 \\
\hline $\mathbf{3}$ & 0.94 & 0.86 & 0.78 & 13 & 0.96 & 0.74 & 0.74 \\
\hline 4 & 1.02 & 1.02 & 0.68 & 14 & 0.81 & 0.92 & 0.71 \\
\hline $\mathbf{5}$ & 0.80 & 0.97 & 0.78 & 15 & 0.95 & 0.99 & 0.89 \\
\hline 6 & 0.81 & 0.93 & 0.67 & 16 & 0.93 & 1.01 & 0.66 \\
\hline $\mathbf{7}$ & 0.73 & 1.04 & 0.75 & 17 & 0.88 & 0.87 & 0.81 \\
\hline 8 & 1.06 & 1.00 & 0.80 & 18 & 0.91 & 0.86 & 0.72 \\
\hline $\mathbf{9}$ & 0.83 & 0.96 & 0.80 & 19 & 0.74 & 1.01 & 0.78 \\
\hline 10 & 0.94 & 0.98 & 0.71 & 20 & 0.82 & 0.92 & 0.81 \\
\hline
\end{tabular}




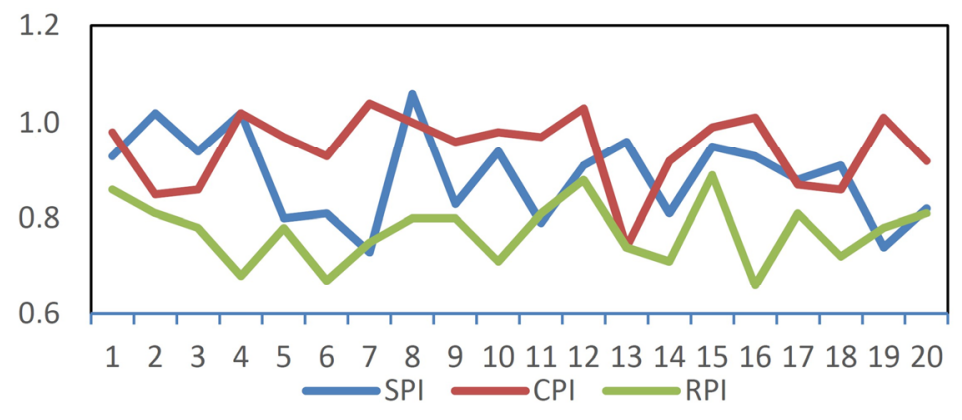

Fig. 1 Data Collection

Table 2 Fuzzy numbers for each linguistic term[35]

\begin{tabular}{|l|l|}
\hline Linguistic terms & \multicolumn{1}{|c|}{$\begin{array}{c}\text { Fuzzy Triangular } \\
\text { Number }\end{array}$} \\
\hline Very low (VL) & $(0,0,0.25)$ \\
\hline Low (L) & $(0,0.25,0.5)$ \\
\hline Medium (M) & $(0.25,0.5,0.75)$ \\
\hline High (H) & $(0.5,0.75,1)$ \\
\hline Very high (VH) & $(0.75,1,1)$ \\
\hline
\end{tabular}

Table 3 Pairwise comparison of indexes using the Z-Number

\begin{tabular}{|l|l|l|l|}
\hline Indexes & $S P I$ & $C P I$ & $R P I$ \\
\hline SPI & $((1,1,1),(1,1,1))$ & $((1,2,5), \mathrm{H})$ & $((2,4,6), \mathrm{L})$ \\
\hline CPI & & $((1,1,1),(1,1,1))$ & $((5,7,9), \mathrm{L})$ \\
\hline RPI & & & $((1,1,1),(1,1,1))$ \\
\hline
\end{tabular}

Table 4 Weight factors corresponding to performance indexes using Z-AHP

\begin{tabular}{|l|l|l|}
\hline Indexes & Weights & $\begin{array}{l}\text { Normalized } \\
\text { Weights }\end{array}$ \\
\hline$S P I$ & 0.96 & 0.44 \\
\hline$C P I$ & 1.00 & 0.46 \\
\hline$R P I$ & 0.22 & 0.10 \\
\hline
\end{tabular}

Using experts' judgments and after fitting appropriate linear functions, the utility functions of SPI, CPI, and RPI are expressed as shown in Eqs. (22) - (24):

$$
\begin{aligned}
& \mathrm{U}(\mathrm{SPI})=3.03 * \text { SPI }-2.21 \\
& \mathrm{U}(\mathrm{CPI})=3.33 * \text { CPI }-2.47 \\
& \mathrm{U}(\mathrm{RPI})=4.35 * \text { RPI }-2.87
\end{aligned}
$$

As can clearly be seen, there is a positive relationship between SPI, CPI, RPI, and their utility functions in Eqs. (22) - (24). In this case, decision making is difficult and the total aggregated utility function is being considered for further processing.

\section{Defining the Fuzzy Membership Functions}

It is supposed that the production manager wishes to accomplish the production process through the SPI range [0.6, 0.85]. The CPI index range is assumed as [0.8, 0.95]. The RPI index requires an acceptable interval for the quality performance index membership function 
of $\left[\mathrm{RPI}^{-}=0.65, \mathrm{RPI}^{+}=0.9\right]$. The level of satisfaction for each performance index is assumed to be uncertain, with related membership functions given in Eqs. (25) - (27).

$$
\begin{aligned}
& \mu[U(S P I)]=\frac{(3.03 * S P I-2.21)-0.6}{0.85-0.6} \\
& \mu[U(C P I)]=\frac{(3.33 * C P I-2.47)-0.8}{0.95-0.8} \\
& \mu[U(R P I)]=\frac{(4.35 * R P I-2.87)-0.65}{0.9-0.65}
\end{aligned}
$$

By substituting the membership function into the model (2) and by using the weights obtaining Z-AHP from Table 4, the model (28) is obtained: The last three inequalities of model (28) indicate that the three utility functions of the indexes (SPI, CPI and $R P I)$ are equal to or less than the desired utility level.

$$
\begin{aligned}
& \operatorname{Max} Z=0.44 * \lambda_{S P I}+0.46 * \lambda_{C P I}+0.1 * \lambda_{R P I} \\
& \lambda_{S P I} \leq \mu[U(S P I)]=\frac{(3.03 * S P I-2.21)-0.6}{0.85-0.6} \\
& \lambda_{C P I} \leq \mu[U(C P I)]=\frac{(3.33 * C P I-2.47)-0.8}{0.95-0.8} \\
& \lambda_{R P I} \leq \mu[U(R P I)]=\frac{(4.35 * R P I-2.87)-0.65}{0.9-0.65} \\
& 3.03{ }^{*} S P I-2.21 \leq U \\
& 3.33^{*} C P I-2.47 \leq U \\
& 4.35{ }^{*} R P I-2.87 \leq U \\
& \lambda_{S P I}, \lambda_{C P I} \text { and } \lambda_{R P I} \in\left[\begin{array}{ll}
0 & 1
\end{array}\right]
\end{aligned}
$$

Model (28) can be transformed into the following model (29):

$$
\begin{aligned}
& \operatorname{Max} Z=0.44 * \lambda_{S P I}+0.46 * \lambda_{C P I}+0.1 * \lambda_{R P I} \\
& 3.03 * S P I-0.25 * \lambda_{S P I} \geq 2.81 \\
& 3.33 * C P I-0.15 * \lambda_{C P I} \geq 3.27 \\
& 4.35 * R P I-0.25 * \lambda_{R P I} \geq 3.52 \\
& \lambda_{S P I}, \lambda_{C P I} \text { and } \lambda_{R P I} \in\left[\begin{array}{ll}
0 & 1
\end{array}\right]
\end{aligned}
$$

Also, using this approach for solving the fuzzy multiple-objective programming, the optimum solution can be expressed as: $\mathrm{SPI}=1, \mathrm{CPI}=1, \mathrm{RPI}=0.87$.

With reference to the above solution, the optimum case is given and the production manager can set up the $S P I, C P I$, and $R P I$ of 1,1 and 0.87 respectively.

Due to conflicting objectives, a compromising policy would be implemented. Here, the production manager has to accept 13 percent of the risks associated with the production process. It means that a zero risk system is not economically sound. To the best of our knowledge, this is the first time that risk performance has been used in the EVM relevant calculations using a fuzzy multiple objective utility model.

\section{Sensitivity analysis}

The last three inequalities of model (27) determine that the three utility functions of the indexes (SPI, CPI and RPI) are equal to or less than the Utility values $(U)$, as shown in Eq. (30).

$$
\begin{aligned}
& 3.03 * S P I-2.21 \leq U \\
& 3.3{ }^{*} C P I-2.47 \leq U \\
& 4.35 * R P I-2.87 \leq U
\end{aligned}
$$


The utility of indexes SPI, CPI and RPI in 5 cases of utility constraint is shown in Figs. 2 - 4. These 5 cases are $U$ equal to $0.8,0.85,0.9,0.95$ or 1 .

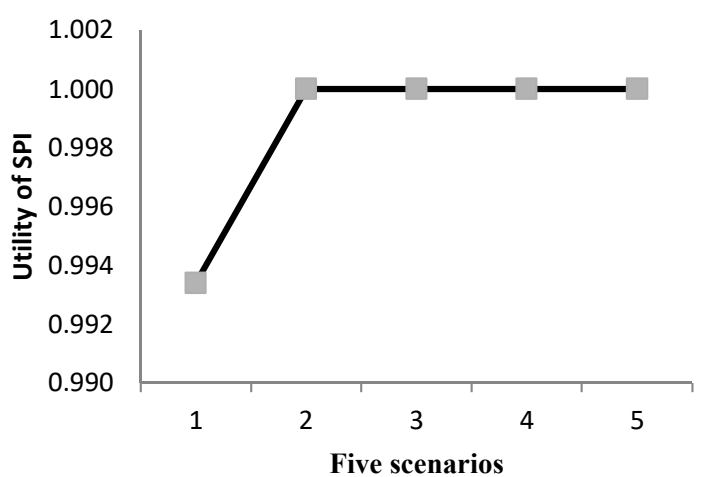

Fig. 2 Utility of SPI in 5 scenarios

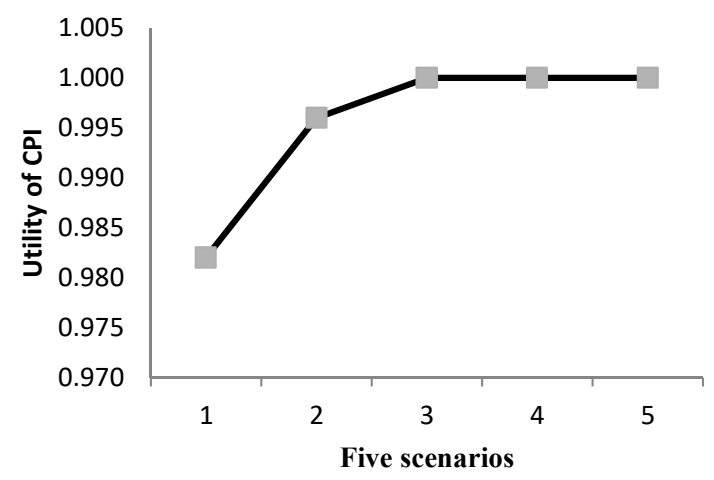

Fig. 3 Utility of CPI in 5 scenarios

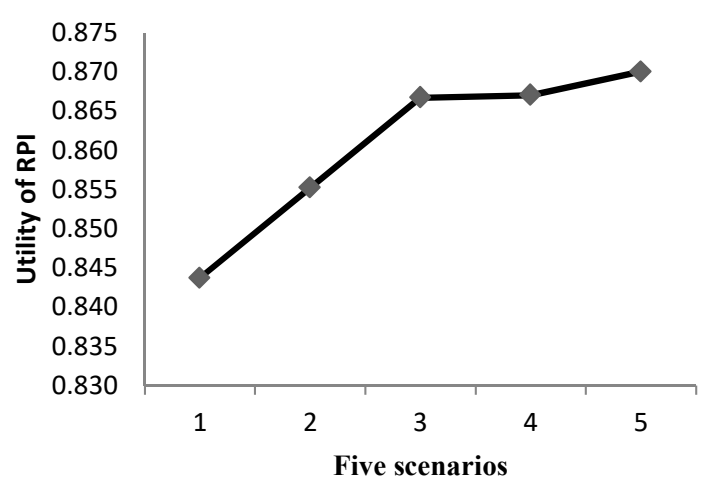

Fig. 4 Utility of RPI in 5 scenarios

\section{Research findings}

The introduction of a novel model in this paper has yielded the following results:

- According to the Z-AHP approach, the importance given to the schedule and the cost performance index is almost the same (approximately 45 percent) and significantly bigger than the importance given to the risk management (approximately 10 percent). It does make sense since "always on-time and on-budget" delivery is an ideal for any production/operations manager. However, risk management may affect the on-time and the on-budget delivery and should therefore be carefully taken into account.

- In this paper, the results obtained after running the optimization problem revealed the optimal SPI and CPI which are equal to 1 and RPI $=0.87$. The result again does make sense to an experienced manager who is really eager to deal with the schedule and the cost performance rather than with unknown risks. The other significant finding from this paper is that it is not practically possible for the risk performance to reach 1 . If an individual wants to manage all risks associated with the production performance index, the process is too intensive and therefore it might be unaffordable to manage all risks. The results imply that 13 percent of risk factors have remained and it is not logical that the risk performance will reach one. So, we accepted that the 13 percent risk might be further associated with the production process.

- Running the sensitivity analysis for SPI revealed that, in most cases, the time performance has to reach the ideal $(\mathrm{SPI}=1)$ and it is always important for any 
production/operations manager to achieve this since we do not want to lose out on a potential customer (due to a delay in the product delivery)

- Running sensitivity analysis for CPI indicated that, in some cases, CPI should reach one. However, if an event happens out of our control, in 40 percent of cases it is possible to create a gap from an ideal condition.

- According to membership function and the importance given to the risk performance index, it is still possible to encounter a lower RPI than expected. The sensitivity analysis deals with lower cases of RPI than the optimal solution.

- Fortunately, it is determined that SPI, CPI, or RPI are not sensitive to the initial condition and a changing scenario did not make a significant difference in the results obtained after running our proposed mathematical model. The model and the obtained results are therefore reliable enough to be considered.

\section{Concluding remark and further recommendations}

In this paper, a multi-attribute utility function is employed to measure the overall manufacturing performance profile. The overall utility function is incorporated into SPI, CPI, as well as RPI. The approach proposed in this paper presents a novel approach for measuring the risk performance index; the approach also yields an integrated utility function. For the sensitivity analysis, the utility of three indexes in 5 cases of utility with risk performance indexes equal to or less than $0.8,0.85,0.9,0.95$, and 1 is developed, demonstrating maximum sensitivity as compared to the other affecting factors. The proposed approach can be further incorporated using the fuzzy type II through the multi-attribute utility theory for future research. As a further recommendation, the obtained results can be entered into a control chart. Also, a decision support system for performing corrective action may be developed. Moving under control limits implies that the performance profile is under control and that just maintaining the current status is required.

\section{Acknowledgement}

The authors would like to thank the Islamic Azad University, Shiraz Branch, Iran. The research carried out for this paper was financially supported by the Islamic Azad University, Shiraz Branch, Iran, through the project entitled "Developing a Novel Controlling Model for Project Cost, Time, and Quality Utilizing Multivariate Control Charts (No 463)".

\section{REFERENCES}

[1] Q. W. Fleming, J. M. Koppelman: Earned Value Project Management. Project Management Institute, 2010.

[2] M. Vanhoucke: Project Management with Dynamic Scheduling: Baseline Scheduling, Risk Analysis, and Project Control. Verlag Berlin Heidelberg, Springer, 2012. https://doi.org/10.1007/978-3-642-25175-7

[3] W. H. Lipke: Earned Schedule, Chicago: Lulu, 2009.

[4] M. R. Feylizadeh, A. Hendalianpour, M. Bagherpour: A fuzzy neural network to estimate at completion costs of construction projects. International Journal of Industrial Engineering Computations, 2012, Vol. 3(3), pp. 477-484. https://doi.org/10.5267/j.ijiec.2011.11.003

[5] F. T. Anbari: Earned Value Project Management Method and Extensions. Project Management Journal Vol. 34(4), 2003, pp. 12-23.

[6] M. Bagherpour, S. Noori: Cost Management System within Production Environment: A performance based approach. IMECHE, Part B: Journal of Engineering Manufacture Vol. 226(1), 2011, pp.145-153. https://doi.org/10.1177/0954405411404303

[7] A., Zareei, S. Noori, Bagherpour: Fuzzy Earned value analysis in production planning problems. Journal of Uncertain Systems Vol. 5(1), 2011, pp. 21-32. 
[8] M. Bagherpour, A. Kamyab Nia, M. Sharifian Mahdavi Mazdeh: Time Driven Activity Based Costing in Production Environments. IMECHE: Part B: Journal of Engineering Manufacture Vol. 227(14), 2012, pp. 333-337.

[9] W. H. Lipke: New Book: Earned Schedule. The Measurable News, Issue 2, 2010.

[10] M. Bagherpour: An Extension to Earned Value Management. Cost Management Vol. 25(3), 2011, pp. 4147.

[11] S. Noori, M. Bagherpour, A. Zareei: Applying Fuzzy Control Chart in Earned Value Analysis: A New Application. World Applied Sciences Journal Vol. 3(4), 2008 pp. 684-690.

[12] S. T. H. Mortaji, M. Bagherpour, S. Noori: Fuzzy Earned Value Management Using Fuzzy L-R number. Journal of Intelligent and Fuzzy Systems Vol. 24(2), 2013, pp.323-332.

[13] S. Jain, K. P. Triantis, S. Liu: Manufacturing performance measurement and target setting: A data envelopment analysis approach. European Journal of Operational Research Vol. 214(3), 2011, pp. 616626. https://doi.org/10.1016/j.ejor.2011.05.028

[14] B. Öztayşi, Ĭ. Uçal,ISAHP: Comparing MADM techniques for use in performance measurement. The 10th International Symposium on the Analytic Hierarchy Process Proceedings, 2009.

[15] B Öztayşi, İ. U. Sari: Performance measurement of a manufacturing company using fuzzy analytical network process. International Journal of Applied Management Science Vol. 4(4), 2012, pp. 439-459. https://doi.org/10.1504/IJAMS.2012.049929

[16] M. Striteska: Key Features of Strategic Performance Management Systems in Manufacturing Companies. Procedia Social and Behavioral Sciences Vol. 58, 2012, pp. 1103-1110. https://doi.org/10.1016/j.sbspro.2012.09.1091

[17] K. Ahmad, S. M. Zabri: The Application of Non-Financial Performance Measurement in Malaysian Manufacturing Firms. Procedia Economics and Finance Vol. 35, 2016, pp. 476-484. https://doi.org/10.1016/S2212-5671(16)00059-9

[18] T. Hayashida, I. Nishizaki, Y. Ueda: Multi-attribute Utility Analysis for Policy Selection and Financing for the Preservation of the Forest. European Journal of Operational Research Vol. 200(3) 2010, pp. 833843. https://doi.org/10.1016/j.ejor.2009.01.035

[19] P. Valenzuela, J. Palma, S. Vega: Dust suppressant treatments. Quality control. Revista de la Construcción Vol. 13(3), 2014, pp. 27-35. https://doi.org/10.4067/S0718-915X2014000300004

[20] A. M. Carvajal, P. Maturana, C. Pino, J. Poblete: Analysis of the Relation between Accelerated Carbonation, Porosity, Compressive Strength and Capillary Absorption in Concrete, in the Search of a New Control Method by Durability. Revista de la Construcción Vol. 8(2), 2009, pp. 129-135.

[21] T. Hirata, A. Ijichi, M. Oshiro, C. Gakiya, K. Kuwae, A. Shimabukuro, S. Tamaki: Development of Quality Control and Breeding Management System of Goats Based on Information and Communication Technology. Studies in Informatics and Control Vol. 22(1), 2013, pp. 81-90. https://doi.org/10.24846/v22i2y101309

[22] A. Ragab, M. El-Sehiemy, A. El-hosseini, A. E. Hassanien: Multi-objective Real-Coded Genetic Algorithm for Economic/Environmental Dispatch Problem. Studies in Informatics and Control Vol. 22(2), 2013, pp.113-122.

[23] M. Subotic, M.Tuba: Parallel and Distributed Software Assessment in Multi-Attribute Decision Making Paradigm. Studies in Informatics and Control Vol. 23(2), 2014, pp. 133-142.

[24] M. R. Feylizadeh, M. A. Dehghani: Priority Determination of the Renewable Energies Using Fuzzy Group VIKOR Method; Case Study Iran. International Conference on Industrial Engineering and Operations Management Kuala Lumpur, Malaysia, 2016, pp. 3281-3287.

[25] M. Bagherpour, M. R. Feylizadeh, D. F. Cioffi: Time, cost, and quality trade-offs in material requirements planning using fuzzy multi-objective programming. Proceedings of the Institution of Mechanical Engineers, Part B: Journal of Engineering Manufacture Vol. 226(3), 2012, pp. 560-564. https://doi.org/10.1177/0954405411424001

[26] S. Noori, M. R. Feylizadeh, M. Bagherpour, F. Zorriasatine, R. M. Parkin: Optimiztion of Material Requirement Planning by fuzzy multi-objective linear programming. Proceedings of the Institution of Mechanical Engineers, Part B: Journal of Engineering Manufacture Vol. 222(7), 2008, pp. 887- 900. https://doi.org/10.1243/09544054JEM1014

[27] A. Amid, S. H. Ghodsypour, C. O'Brien: A weighted max-min model for fuzzy multi-objective supplier selection in a supply chain. Int. J. Production Economics Vol. 132(1), 2011, pp. 162-163. https://doi.org/10.1016/j.ijpe.2011.03.001 
[28] G-H Tzeng, J-J Huang: Multiple Attribute Decision Making: Methods and Applications. CRC Press, Taylor and Francis Group, 2011.

[29] S Parsaei, M Keramati, F Zorriassatine, M. R. Feylizadeh: An order acceptance using FAHP and TOPSIS methods: A case study of Iranian vehicle belt production industry. International Journal of Industrial Engineering Computations Vol. 3 (2), pp. 2112-224.

[30] N. Jamali, M. R. Feylizadeh: Performance Evaluation of Aircraft Maintenance Department Using Integration Fuzzy AHP and BSC Approach in Iran. International Journal of Management, Accounting and Economics Vol. 2, 2015, pp. 977-993.

[31] A. Azadeh, M. Saberi, N. Zandi Atashbar, E. Chang, P. Pazhoheshfar: Z-AHP: A Z-number Extension of Fuzzy Analytical Hierarchy Process. 7th IEEE International Conference on Digital Ecosystems and Technologies. 2013, pp. 141-147. https://doi.org/10.1109/DEST.2013.6611344

[32] L. A. Zadeh: A Note on Z-numbers. Information Sciences Vol. 181, 2011, pp. 2923-2932. https://doi.org/10.1016/j.ins.2011.02.022

[33] B. Kang, D. Wei, Y. Li, Y. Deng: A method of converting Z-number to classical fuzzy number. Journal of Information and Computational Science Vol. 9(3), 2012, pp. 703-709.

[34] M. Salari, M. Bagherpour, J. Wang: A novel earned value management model using Z-number. International Journal of Applied Decision Sciences Vol. 7(1), 2014, pp. 97-119. https://doi.org/10.1504/IJADS.2014.058037

[35] Y-H Chen, T-C Wang, C-Y Wu: Strategic decisions using the fuzzy PROMETHEE for IS outsourcing. Expert Systems with Applications Vol. 38(10), pp. 13216-13222.

https://doi.org/10.1016/j.eswa.2011.04.137

Submitted: $\quad 11.8 .2016$

Accepted: $\quad 28.9 .2017$
Mohammad Reza Feylizadeh

(Corresponding author)

Department of Industrial Engineering, Shiraz Branch, Islamic Azad University, Shiraz, Iran

Feylizadeh@iaushiraz.ac.ir

Morteza Bagherpour

Department of Industrial Engineering

Iran University of Science and

Technology, Iran

bagherpour@iust.ac.ir 